\title{
De la ficción a la urgencia informativa: la matanza de Utoya y el análisis prospectivo de Stieg Larsson
}

\author{
Fermín GALINDO ARRANZ \\ fermin.galindo@usc.es \\ Universidad de Santiago de Compostela
}

Recibido: $21 / 02 / 2013$

Aceptado: 24/09/2013

\begin{abstract}
Resumen
La violenta irrupción en todas las redacciones del atentado de Oslo y de la Matanza de Utoya llevó a la profesión periodística a buscar una explicación inmediata de los hechos. El análisis informativo habitual no alcanzaba a comprender las causas de lo acontecido y, los antecedentes internacionales remitían a otros conflictos ajenos a la situación. La opinión pública internacional buscó en la obra del escritor sueco Stieg Larsson, autor de la trilogía Millennium y director de la revista Expo, la explicación profunda de los atentados. El análisis de las crónicas publicadas en la prensa española los días posteriores al atentado, corrobora el agrio diagnóstico político y social, que se encuentra detrás del éxito de la novela negra escandinava actual.

Palabras clave: Urgencia informativa, ficción, Stieg Larsson, Eva Gabrielsson, Oslo, Utoya, visión artísitica, opinión pública internacional

\section{From fiction to informative urgency: the killing of Utoya and the prospective analysis of Stieg Larsson}

\begin{abstract}
The violent irruption in all newsrooms of the Oslo terrorist attack and the killings of Utoya lead journalists to look for an inmediate understanding of the facts. The usual informative analysis wasn't able to explain the causes of what had happenef and the international background directed to other conflicts unrelated to that situation. International public opinion looked for the deep explanation to the attacks in the Swedish writer Stieg Larsson's trilogy Millenium. The analysis of the chronicles published in the Spanish press the days after the attack corroborates the bitter political and social diagnosis that is behind the success of Scandinavian present day thrillers.
\end{abstract}

Keywords: Informative emergency, fiction, Stieg Larsson, Eva Gabrielsson, Oslo, Utoya, artistic view, international public opinion.

\section{Referencia normalizada}

GALINDO ARRANZ, Fermín (2013): "De la ficción a la urgencia informativa: la matanza de Utoya y el análisis prospectivo de Stieg Larsson“. Estudios sobre el Mensaje Periodístico. Vol. 19, Núm. 2 (juliodiciembre), págs.: 703-714. Madrid, Servicio de Publicaciones de la Universidad Complutense.

Sumario: 1. Introducción. 2. Millenium, una ficción con denominación de origen. 3. Del periodismo de agencia a la revista Expo. 4. Utoya un estudio de caso entre la urgencia informativa y el género negro. 5. Conclusiones. 6. Referencias.

\section{Introducción}

El escritor sueco Stieg Larsson es mundialmente conocido como autor de novela negra y de la trilogía Millennium. Ante el éxito mundial de sus bestsellers sus artículos periodísticos han quedado en un segundo plano de su obra. La matanza de Utoya del 22 de julio de 2011 ha devuelto a la actualidad su trabajo como director de la revista Expo. Al valor de su obra literaria que emerge de un profundo conocimiento del lado más oscuro de la realidad social escandinava, se une ahora el reconocimiento de la opi- 
nión pública sobre su visión política y su capacidad de anticipación a los acontecimientos.

\section{Millenium, una ficción con denominación de origen}

En los últimas décadas los países escandinavos gozaban de una imagen reconocible a nivel mundial por su elevado nivel de vida, su organización y conciencia social, su respeto al medio ambiente, sus valores cívicos y en general como un grupo de sociedades prosperas y saludables. A mediados de los noventa el escritor Carlos Casares (2012: 48), conocido divulgador de sus valores a través de sus artículos, contaba: "Cando cheguei a Suecia por primeira vez, hai case vintecinco anos, eran moitas as cousas que me asombraban. En primeiro lugar a amabilidade da xente, tan correcta no trato. Despois, o nivel de vida, infinitamente superior non só o que había na España daquel tempo, senón ó que eu tiña descuberto, con verdadeira envexa, en outros países de Europa, incluida Suiza”. Para Casares las libertades no eran formales, eran reales; no había pobreza; la policía no tenía nada que ver con la española o la francesa; el nivel de vida era altísimo y la igualdad extraordinaria.

Escandinavia conoce dos estaciones, ambas fuertes envites del tiempo: un largo invierno y un verano corto. El tiempo de verano también tiene connotaciones idílicas. Durante estos meses, Suecia ${ }^{1}$ revive y se abre como una revelación; en Estocolmo, es el tiempo de explorar el archipiélago, es una forma de buscar el stämning². Los suecos descubren el esplendor de la hierba, por fin despojada de la nieve, y la caricia del sol en la piel. El anhelo de que acabe más de medio año de frío y la esperanza de que el verano sea espléndido, cálido, como el de una infancia lejana, de surcar el mar en velero o de pasear por los bosques. En resumen, la gente ve en Suecia una sociedad del bienestar avanzada que renueva su optimismo cada verano.

Todo esto era así hasta el éxito de la novela negra escandinava. En la primavera de 2012 Mari Jungstedt presentó en Palma de Mallorca su último libro: "Un inquietante amanecer". La escritora considera que parte del éxito de sus relatos está en que cuando leen sus novelas ven el la otra cara, el lado oscuro de su país. Mari Jungstedt ha publicado cinco novelas en español, de la decena que ha escrito, en ella narra unos misteriosos asesinatos en los islotes de Gotland ${ }^{3}$, incluido un campista de la playa de Fårö. Un argumento demasiado familiar en las noticias del último año. Sólo unos años antes, Stieg Larsson había revelado al mundo con su saga Millennium un mundo oscuro y violento junto al Báltico. La trilogía emerge de una violencia cifrada en términos sociales que aparece ligada a los comportamientos de una singular heroína Lisbeth Salander. Fiel a su particular sentido de la moral protagoniza escenas con un elevado grado de crueldad y que se sitúan a medio camino entre los social y el rito. (L. Santos, 2012: 449) La violencia de sus acciones y de sus textos se encuentra salpicada de referencias bíblicas y se inserta en una estética gótica que acentúa su dramatismo. En

1 Ronda Iberia Magazine, “Ambiente de Suecia”, Madrid, pg 76-86. 3/2012

2 Es un concepto que hace referencia a la búsqueda de una atmósfera equilibrada de ambiente sosegado y melancólico.

3 En EFE, Copenhague, 28/4/2012 
este sentido, López Santos (2011) destaca el comportamiento de Gottfried Vanger y explica como sus acciones responden a motivaciones rituales disfrazadas de razonamientos seudorreligiosos, favorecidas por las referencias a la Biblia, en concreto a determinados pasajes del Levítico. Sus actos, de una violencia sexual extrema, como los de su padre Martín, siguen unas pautas fijadas y trasmitidas a modo de herencia: todos cometidos en pequeñas poblaciones, en lugares inhóspitos y siempre a mujeres débiles e indefensas, en parajes recónditos y en lugares descritos como auténticas cámaras de los horrores. Nada más alejado del hasta entonces consenso generalizado sobre el imaginario social de la idílica Suecia.

\section{Del periodismo de agencia a la revista Expo}

En el libro "Millennium, Stieg y yo" (2011) Eva Gabrielsson relata su vida junto a Stieg Larsson y desvela muchas de las claves que encierran sus novelas. Su infancia, sus paisajes, su lucha por la supervivencia, sus valores, sus afectos y desafectos, son sólo algunas de las circunstancias que trenzan sus páginas. Eva Gabrielsson, arquitecta de profesión, compartió su vida con Stieg desde sus mayoría de edad aunque la pareja nunca contrajo matrimonio como medida de protección contra los ataques de grupos de ultraderecha. El escritor murió de un ataque al corazón en 2004. No pudo ver su éxito, ya que falleció poco después de entregar su tercer volumen en la editorial. A la muerte del periodista, Eva se quedó sin derecho alguno sobre el legado de Larsson, incluso sobre su propia vivienda. Este libro constituye, además de un testimonio sobre la obra del autor, un intento por conseguir algún tipo de control, moral o económico, sobre la obra de su compañero. La periodista Marie-Françoise Colombani colabora con Gabrielsson a la hora de ordenar sus recuerdos y también a la hora de aportar su testimonio en la disputa familiar por los derechos de la trilogía Millennium.

En una visita a España uno de sus compañeros el reportero kurdo Baksi presentó el libro y contó quién era ese periodista que escribía ficción a escondidas una vez terminada su jornada laboral. A juicio de Baksi tres palabras definían a Larsson: raza, sexo y clase. "Consideraba que si vivimos en un mundo en el que la mujer, los inmigrantes y los pobres no tienen el mismo valor que sus conciudadanos, es que este mundo es malo". Y definía a Larsson con una sencilla fórmula: "un $25 \%$ de sueco tímido, un $50 \%$ de Teresa de Calcuta y un $25 \%$ de soñador".

Eva Gabrielsson (2011: 57) cuenta como en 1979 Stieg dejó su trabajo en correos y se incorporó a TT -Tidningarnas Telegrambyrå- (la agencia EFE sueca). Al principio trabajó allí en labores administrativas, durante veinte años fue reportero y pasó a escribir sobre todo tipo de temas: "desde Darwin a Robin Hood, pasando por la segunda guerra mundial, sin olvidarse de la novela negra, que era una de sus especialidades". Explica que le gustaban especialmente aquellas escritas por mujeres y que su cultura era muy ecléctica, como suele corresponder a una formación autodidacta. Cuenta como en su casa había libros por todas partes de cualquier tema: ciencia ficción, política, espionaje, feminismo, informática, etc. Stieg Larsson tenía curiosidad por cualquier cosa.

A mediados de la década de los ochenta los militantes de extrema derecha sueca empezaron a matar gente por motivos racistas o políticos, a atracar bancos para fi- 
nanciar sus movimientos y buscar armamento en robos a instalaciones militares. La sección en la que escribía, Bild \& Features, dedicada a noticias y reportajes, fue clausurada en los noventa y a pesar de su conocimiento del área de tribunales su experiencia fue despreciada por la agencia. En la agencia consultaban a menudo con Stieg Larsson las noticias de sucesos, conocía los antecedentes políticos de los sospechosos, sus cómplices y los ambientes que frecuentaban. En la década de los noventa, la TT, Tidningarnas Telegrambyrå, contaba con la mejor información sobre estos asuntos, no obstante su máximo experto en estas cuestiones nunca alcanzó un contrato laboral fijo en la compañía estatal sueca. Cuenta Eva Gabrielsson (2011: 59) como en 1999, fueron asesinados dos agentes de policía en Malexander, un pueblo a ciento sesenta kilómetros de Estocolmo. La brutalidad de los hechos llamó la atención de Stieg, que puso en relación aquellos crímenes con la extrema derecha, una intuición que más tarde se descubrió que era cierta. La agencia TT no reconocía su valía y tuvo que aceptar finalmente su despido y abandonar la agencia.

A partir de entonces se dedicó a Expo una publicación y una fundación creadas en 1995. No obstante, unos años antes marcado por su infancia junto a su abuelo, un hombre muy comprometido con cuestiones políticas, Stieg quiso colaborar en la revista Searchlight, británica y antifascista, 1982 viajó a Londres y desde entonces colaboraba de forma anónima con la publicación. "Salvo en Searchlight -señala Gabrielsson- firmó siempre sus artículos, informes y libros". En 1991 publicó junto Anna-Lena Lodenius "Extremhögern" (La extrema derecha), un libro en el que se catalogaban los grupos y los partidos de esta corriente, desvelaban sus raíces, sus socios en Europa y en Estados Unidos, así como su uso de la violencia. También, colaboró con el politólogo francés Jean-Yves Camus, en la obra Los extremismos en Europa, redactando la parte escandinava. Su nombre era conocido y pasó a estar amenazado por los grupos de ultraderecha.

En aquella época cualquier persona podía obtener la fotografía de un vecino acudiendo a la policía que se encargaba de los pasaportes. Sus novelas no son ajenas a estas circunstancias vitales y los personajes intentan mantener su privacidad en un estado de alarma permanente cuando no de abierta clandestinidad. Gabrielsson (2011: 70) señala como En Los hombres que no amaban a las mujeres, Lisbeth Salander explica la simplicidad del trámite: "Si el individuo en cuestión aparecía en algún registro informático, la presa caería inmediatamente". O como sucede en el siguiente volumen La chica que soñaba con una cerilla y un bidón de gasolina la protagonista duda en mudarse a otro apartamento ya que por el simple hecho de cambiar de domicilio se convierte en una persona presente en todo tipo de ficheros. Durante la década de los noventa se produjeron más de una docena de asesinatos a manos de extremistas y miles de agresiones nazis. Stieg fue amenazado, aunque su nombre no figuraba en su buzón recibía todo tipo de anónimos, incluso balas por correo. Vivía en un apartamento a nombre de Eva rodeado de medidas y rutinas de seguridad, tal y como lo hace Lisbeth Salander en sus novelas.

$\mathrm{Su}$ compañero Baksi ha querido ver en el personaje de Blomkvist un alter ego de Larsson. El periodista que le hubiera gustado ser. "Blomkvist es mujeriego y Larsson era muy tímido con las mujeres; Blomkvist era un periodista efectivo y fuerte y Lars- 
son, no; Blomkvist direge Milleniun una revista de éxito y Larsson Expo, por entonces un proyecto perdedor". Como nos cuentan los más próximos este cúmulo de informaciones constituye la argamasa de su obra narrativa y periodística; aparece entonces un asunto de interés: la conexión informativa de Stieg Larsson con la vida cotidiana y su visión para elegir su lado más oscuro a la hora de interpretar la realidad social.

Con estos mimbres, acumulados en sus tres décadas de periodismo de investigación, con un conocimiento profundo de la Suecia rural adquirido en una infancia difícil, con sus múltiples y eclécticas lecturas, con sus conversaciones de arquitectura con Eva y con la infinidad de cafés compartidos con su colegas; con las sentidas ausencias de algunos de sus familiares más próximos y con su permanente compromiso antifascista, va tejiendo un universo narrativo propio, extremadamente violento y, que de forma extraña conforma una ficción creíble por inaudita. Stieg Larsson escribe compulsivamente todo tipo de textos, artículos de debate, libros, documentos y, sobre todo, novela negra en la vuelca todas sus convicciones.

En el $\mathrm{n}^{\mathrm{o}} 1$ de la revista Expo anticipa: "En Estocolmo también pueden producirse atentados terroristas". El propio director Stieg Larsson advertía que el atentado terrorista que había tenido lugar en Oklahoma City el 19 de abril de 1995 también podía producirse en Suecia. Larsson explica como la bomba, además de una explicación política e histórica, tenía un antecedente literario directo: lo ocurrido en Oklahoma City no fue ninguna catástrofe natural, sino un asesinato en masa meticulosamente planeado y llevado a cabo conscientemente y, señalaba, The Turner Diaries (Los diarios de Turner, 1978) de William L. Pierce como el libro inspirador del atentado en Oklahoma de 1995 y de ataques futuros.

La sociedad sueca tenía ya algún antecedente traumático previo como el asesinato de Olof Palme en 1986 o el de la ministra de Asuntos Exteriores Anna Lindh en 2003. Carlos Casares (2012: 51) recuerda como un día después del magnicidio de Olof Palme escribía en La Voz de Galicia un artículo en el que afirmaba que lo peor de aquella muerte absurda era que con toda probabilidad, el autor había de ser "calquera estúpido, quizais por razóns no menos bobas". No sabía de aquella iba a ser tan cierto lo que pensaba. Cuando vio al acusado por televisión, durante el juicio, quedó asombrado del personaje y eso que no llegó a imaginar a un elemento como Breivik. Larsson (2011: 38) los conocía bien: "Cabe destacar que casi todos esos «locos solitarios» son miembros de -o están vinculados a- grupos donde se predica la leaderless resistance". Una especie de resistencia sin líderes que da lugar a un terrorismo espontáneo realizado por unos entregados y convencidos soldados políticos. De esta forma explica Larsson el terrorismo no está organizado por un grupo específico y que no hay líderes formales. De esta manera les resulta difícil identificar y detener a los malhechores. El terrorismo se convierte así en un acto anónimo, algo así como un movimiento popular que siembre el pánico en la sociedad con todo tipo de actos violentos: atentados con bomba contra tribunales y comisarías, cartas bomba o asesinatos a los traidores a la raza. En 1995, desde las páginas de Expo, Stieg Larsson trazó el retrato robot del autor del atentado de Oslo y la matanza de Utoya. 


\section{Utoya un estudio de caso entre la urgencia informativa y el género negro}

En la tarde del viernes 22 de julio de $2011^{4}$ nadie sabía a ciencia cierta lo que había sucedido. "Terror en Noruega. Noruega era ayer un país estupefacto. En la sede del ejecutivo de Oslo estalló una bomba y un hombre de nacionalidad noruega disparó contra los jóvenes de un campamento". El Mundo titulaba en portada: "Misterioso doble atentado contra el Gobierno Noruego", y en páginas interiores: "El fin de la inocencia. Los noruegos descubren el horror en una explosión de odio de autoría misteriosa". Inicialmente un grupo yihadista reivindicó el atentado y luego se retractó, reconocidos expertos en la materia todavía lo creían así en los análisis publicados al día siguiente (Reinares, 2011, 23/7: 5). El País titulaba: "Dos pistas para un doble atentado. Noruega está bajo amenaza de Al Qaeda desde 2003 por su participación en la guerra de Afganistán, pero no se descarta un ataque de la extrema derecha".

"¿Por qué en Noruega, un país sin más enemigos que los defensores de las ballenas?". Miguel Anxo Murado trataba de buscar una respuesta:

"Quizás la clave esté en otro hecho que ocurrió simultáneamente: el tiroteo, por parte de un hombre vestido de policía, en un campo de verano del Partido Laborista noruego. Si los dos hechos están relacionados, y es seguro que lo están, esta insistencia en el partido del Gobierno parece indicar un móvil doméstico, quizá un ataque de la extrema derecha (improbable porque no existen precedentes en Noruega) o quizás un francotirador solitario, un individuo con algún trastorno o agravio personal que podría haber colocado los explosivos y atacado luego el campamento. La voladura de un edificio gubernamental, de hecho, recuerda al atentado de Oklahoma City de 1995, obra de un solitario norteamericano de extrema derecha. El cóctel anti-Bruselas, antiinmigración y anti-Estado está resultando un éxito como caldo de cultivo para la nueva extrema derecha escandinava". (Murado, 2011, La Voz de Galicia, 23/7: 3)

El Mundo sostiene en su editorial: "Ninguna de las novelas escandinavas del género negro ofrece un relato tan sobrecogedor como el episodio real que ha golpeado Noruega. El noruego Anders Behring reconoció ante la policía la autoría de los hechos. Pero aún falta esclarecer si tuvo algún cómplice para perpetrar la mayor masacre en Noruega desde la segunda guerra mundial". Ningún periódico coincide en el número de victimas y heridos. Inicialmente siete en Oslo y diez en Utoya, luego decenas de muertos, más tarde el recuento de victimas se acerca al centenar, cada periódico da una cifra aproximada, ninguna es correcta. No sirven los análisis políticos y ante la gravedad de los hechos se mira a los autores de novela negra en los que se busca el espejo literario de la sociedad.

Los titulares destacan como los autores de novela negra han sacado a la luz los claroscuros del país, como el apoyo al nazismo de un amplio sector de la sociedad y su resurgimiento a partir de los noventa. Guillermo Altares incidía desde las páginas de El País en el mismo sentido:

${ }^{4}$ Para la realización de este análisis consultamos en la hemeroteca de la USC las ediciones de El País, El Mundo, ABC, Faro de Vigo, La Razón, El Semanal, La Voz de Galicia, Faro de Vigo, El Correo Gallego y Público (23/7 a 31/7 de 2011). Con especial atención a los despachos de EFE y las crónicas enviadas desde Oslo, Rena, Copenhague, Bruselas, Washington y Berlín. 
"Si hay un fenómeno que ha marcado el mundo editorial mundial en los últimos años es el boom de las novelas negras nórdicas. Son países muy diferentes; pero tienen características en común, los países y los escritores. Suecos, noruegos, islandeses o finlandeses, que han arrasado en las librerías, reflejan una profunda inquietud, un sentimiento extremo de que algo va mal. Los autores más famosos, los suecos Henning Mankell y su detective Kurt Wallander, y el fallecido Stieg Larsson y su mundo de hackers, periodistas, asesinos y sádicos de todo pelaje reflejan en sus libros ese mal que ha aparecido el viernes en Oslo y en Utoya. Incluso, el noruego Jo Nesbo escenificó un atentado de la ultraderecha en su novela Petirrojo". (Altares, 2011, 24/7: 8)

También, sobre Jo Nesbo, escribe Daniel Vázquez Sallés "Los santos de los últimos días" en El Mundo:

"Anders Behring Breivik podría ser un personaje de una novela del escritor noruego Jo Nesbo, pero no lo es. Las víctimas caídas por la patria de la sinrazón en la isla de Utoya y en el centro de Oslo, entrarán en el Paraíso sin paso previo por el Purgatorio con la certidumbre de haber vivido en sus carnes que la realidad supera muchas veces la ficción, cuando no se retroalimentan".

"El autor de la masacre nos ha ayudado a descubrir una parte oscura de Noruega que, como toda nación cercana a la Aurora Boreal, era considerada hasta hace pocas décadas el paradigma de la democracia sin mellas ni signos disonantes. Han sido los autores de novela negra los que han conseguido romper el mito del Paraíso terrenal. Si Karim Fossum o Anne Holt mantienen alto el pebetero de la novela negra noruega, es Jo Nesbo el que, con mayor obsesión, ha dedicado parte de su oficio de escritor a denunciar el filonazismo subyacente en la sociedad de su país. En su novela Petirrojo cuenta como muchos pájaros fueron colaboradores del nazismo, pero como el petirrojo, gran parte de ellos no emigraron y buscaron guarida en la misma Noruega democrática señalando con el dedo a los colaboradores sin coartada, esperando una primavera en la que fuera más propicio volar sin miedo. Nesbo retrata una Noruega actual en la que las olas migratorias producto de la globalización no han hecho más que instaurar una conciencia filonazi de la patria. En épocas de crisis se buscan chivos expiatorios y es entonces cuando se demuestra que ser santo no es un dogma de fé. La barbarie política cometida, presuntamente, por este nacionalista de extrema derecha llamado Anders Behirng Breivik encierra una verdad incuestionable: los profetas ya no escriben textos sagrados, escriben novela negra". (Vázquez Sallés, 2012, 24/7: 25).

Aunque para el psiquiatra Enrique Rojas (El Mundo, 2011, 25/7: 17) "el carnicero de la isla de Utoya deja corto lo narrado por Jo Nesbo en Petirrojo, que es la historia de un asesino especializado en matar a personas cortándoles la yugular y teñir sus cuellos de rojo carmín".

También hay quien discrepa de esta corriente, en la que siguiendo a Camiñas (2003: 507) se puede considerar una opinión táctica. Así Víctor Lapuente desde El País, $(2011,24 / 7,7)$ atribuye la gran producción de novela negra escandinava a la existencia de unas sociedades capaces de generar productos altamente creativos y exportables, como novelas, canciones o software. Lo cierto es que la incursión que realizó el periodista Jordi Évole en Estocolmo a la ultraderecha nórdica para Salvados (26/11/2010) permiten descartar la hipótesis anterior. Todavía más esclarecedor es el testimonio de un vecino del asesino, sobrecogedor por su naturalidad: "sabía que antes o después 
esto iba a pasar". Ricardo Da Silva Abeijon, gallego afincado en Noruega desde hace 45 años, es entrevistado por Julio Fariñas en La Voz de Galicia:

"Los hechos le tocaron muy de cerca por partida doble: tres horas antes de la explosión del coche bomba en las inmediaciones de la sede del Gobierno, pasó por allí, ya que el lugar está en una de las rutas que hace casi a diario en su trabajo de distribución de vinos. Por si eso fuera poco, cuando vio en televisión la foto de Anders Behring, lo reconoció inmediatamente: era su vecino. La casa dónde vivió, primero con su madre y luego sólo, está a menos de 200 metros de la suya. Se cruzó muchas veces con él por el barrio.

- ¿Que sintió cuando lo vio?

- Me impresiono mucho, pero no me sorprendió. Yo sabía que antes o después eso iba a pasar.

- ¿Por qué?

- No sé, pero allí, entre este tipo de gente, hay mucho racismo. El Gobierno se porta bastante bien con los extranjeros y eso a algunos les sienta muy mal. (Fariñas, 2011, 28/7: 21)

Como ha señalado Guillermo Altares (El País, 2011, 24/7: 8), Larsson conoció muy de cerca los círculos de la ultraderecha nórdica, describió sobre todo una sociedad que se alejaba de la utopía para sumergirse en la realidad de un mundo herido y violento. "En el fondo, nos cuentan que no existen sociedades perfectas, solo seres humanos imperfectos". Un primer diagnóstico del psiquiatra Enrique Rojas es rotundo:

"se trata de un psicópata, o de una personalidad antisocial, cuyos principales síntomas son: patrón de conducta de agresividad a lo grande, llevada a cabo de forma fría y calculada con minuciosidad, estando tranquilo y sabiendo lo que hacía; impulsividad extraordinaria; ausencia de sentimientos de culpa o de arrepentimiento (en casos con menor nivel de agresividad, lo más frecuente es que el sujeto se suicide); tendencia a disfrutar haciendo daño y necesidad de aparecer como un héroe a la inversa y de ser portada de periódicos de medio mundo y de imágenes de televisión sin precedentes". (Rojas, 2011, El Mundo, 25/7: 17)

Así las cosas, cuando redactamos estas páginas el tribunal de Oslo ${ }^{5}$ acaba de anunciar que no se podrán filmar las declaraciones del ultraderechista Anders Behring Breivik durante el juicio que comenzará el 16 de abril en Oslo por los atentados del 22 de julio de 2011, en los que murieron 77 personas. La prohibición de grabar imagen y sonido, y también de hacer fotos, regirá para las comparecencias de los supervivientes del doble atentado y de los forenses encargados de hacer las autopsias a las víctimas. La juez Wenche Elizabeth Arntzen ha explicado que se trata de impedir por todos los medios que el acusado pueda propagar los mensajes que están en el origen de sus actos. Artzen apeló también a la consideración hacia los afectados por los atentados por para no permitir que las explicaciones de Breivik sean incluidas en la retransmisión en directo que se hará del juicio y que los afectados podrán ver en 17 juzgados de Noruega.

5 Ver EFE, Copenhague, 9/3/2012. 
La juez accedía así a la recomendación de los fiscales y de los abogados de los supervivientes y familiares de las víctimas y rechazaba la petición de las asociaciones de la prensa noruegas y del propio imputado, partidario de la retransmisión integra del juicio. Estaba permitido en cambio grabar la lectura de la acusación contra Breivik al inicio del proceso -lo que incluye su declaración de culpabilidad o inocencia-, las explicaciones introductorias de la defensa y la acusación, así como las argumentaciones finales. La corte esperó a recibir las pruebas de la acusación para decidir si permitía filmar las intervenciones de los testigos profesionales, como agentes de policía. Breivik fue acusado formalmente el 7 de marzo de $2012^{6}$ de cometer actos de terrorismo y 77 homicidios voluntarios. Finalmente, las imágenes del acusado y de los atentados han sido reproducidas hasta la saciedad en los informativos de todo el mundo, generándose un intenso debate sobre los efectos de las mismas y la conveniencia de su emisión.

Eva Gabrielsson (El Mundo, 26/7: 19) se ha encargado de recordar que: "las actuales corrientes de pensamiento político no se muestran siempre ni exclusivamente como organizaciones a las que podamos ver en la calle, sino también como foros ideológicos y grupos no muy compactos en internet" algo que Stieg Larsson ya había anticipado en su profecía. Ante la amenaza lejos de achantarse la sociedad noruega ha respondido con más tolerancia, con más respeto y con más democracia. Como ha destacado la escritora Ann-Louise Gulstad (El Mundo, 2012: 21), "la palabra venganza no ha sido pronunciada". Y en medio de todo esto, los noruegos organizaban un barnesang ${ }^{7}$, un concierto infantil, simultáneo y multitudinario en todas las ciudades noruegas de norte a sur. Decenas de niños cantando Barn av regnbuen -Niños del arco irisversión en noruego de My Rainbow Race del cantautor americano Pete Seeger, una canción muy popular traducida al noruego en 1973, y que habla de la necesidad de aprender a vivir juntos, cada hermana y cada hermano, compartiendo el cielo azul y la tierra verde.

\section{Conclusiones}

La inmediatez de la noticia lleva en ocasiones aparejada la dificultad de su en el análisis y su valoración en la dimensión adecuada. En ocasiones la visión del escritor o del artista acierta en mayor mediada a interpretar el discurrir de los acontecimientos. La violenta irrupción en todas las redacciones de los despachos de agencia de la que se denominaría más tarde Matanza de Utoya llevo a la profesión periodística a buscar una explicación de los hechos. El análisis informativo habitual no alcanzaba a explicar las causas de lo acontecido y los antecedentes internacionales remitían a otros conflictos ajenos a la situación. Finalmente la explicación mas profunda de lo vivido la aportan autores y críticos de la exitosa novela negra escandinava de los últimos años.

En este terreno destaca poderosamente la figura de Stieg Larsson y de su saga $\mathrm{Mi}$ llenium, crecida en un sustrato de violencia política y social que se presentaba al resto del mundo como un mero producto de ficción. Las claves de su narrativa, su peripecia vital, y sus textos de denuncia habían sido publicados en Expo antes de su prema-

6 Ver EFE, Copenhague, 7/3/2012.

7 En EFE, Copenhague, 26/4/2012. 
tura muerte. La disputa familiar por los derechos y el uso apropiado de la obra de Siteg Larsson llevó a su compañera Eva Gabrielsson a publicitar un periodismo vigoroso, militante y de denuncia que con el tiempo ha adquirido un carácter profético y en el que la opinión pública termino por encontrar la raíz profunda del mal que acababa de convertirse en noticia.

Frente a un hecho absolutamente excepcional como el atentado de Oslo y la matanza de Utoya el análisis de los despachos y crónicas de enviados y corresponsales de los principales diarios españoles corrobora el acierto en el agrio diagnóstico, político y social, de la novela negra escandinava frente a la interpretación limitada y más superficial del análisis informativo habitual. Como había señalado Stieg Larsson, en este caso la ficción anticipa la realidad aunque desgraciadamente en Utoya fuera superada por esta última.

\section{Referencias}

ALTARES, Guillermo (2011): “¿Qué hubiese dicho Wallander?”, El País, 24/7/2011, p. 8.

CAMIÑAS, Tasio (2003): Los medios de comunicación como soporte de propaganda: El caso de la prensa española de referencia a través de los expertos. Málaga, Universidad de Málaga, Tesis Doctoral (inédita)

CASARES, Carlos (2012): "O encontro con Suecia”. A Coruña, La Voz de Galicia. Biblioteca Gallega, pp. 46-51.

CASTRO, Iñaki (2011): "El autor de la matanza de Noruega es un fanático de la ultraderecha". Bruselas, La Voz de Galicia, 24/7/2011, pg. 2.

CHATILLARD, Gionata (2012): "Breivik, el asesino que no logra parecer cuerdo", Madrid, El Mundo, 8/3/2012, p. 27.

CÓZAR, Álvaro y GÓMEZ, Juan (2011): "79 minutos con Anders Behring Breivik matando" -Reportaje: el monstruo-, Berlín, El País, 31/7/2011.

DESHAYES, Pierre-Henry (2011): "Dos ataques vinculados golpean al gobiernos y los socialistas noruegos", Oslo/AFP, La Voz de Galicia, 23/7/2011, p. 2.

DESHAYES, Pierre-Henry (2011): "Escenas de guerra en el corazón de Oslo", Oslo/AFP, La Voz de Galicia, 23/7/2011, p. 3.

ÉVOLE, Jordi (2010): "La otra cara de la ultraderecha en Suecia" en "Salvados" de 26/11/2010 La Sexta, Barcelona y www.lasexta.com

FARIÑAS, Julio (2011): "Sabía que antes o después esto iba a pasar", entrevista a Ricardo DA SILVAABEIJÓN, en La Voz de Galicia, 28/7/2011, p. 21.

GALLEGO, Javier (2011): “Un policía os va a informar”. Oslo, El Mundo, 24/7/2011, p. 1,22 y 23.

GARCÍA MANZANO, Eduardo (2012): "Los hombres que odiaban a Sieg Larsson". en MientrasTanto.org, tomado el 2/2/2012.

GÓMEZ, Juan (2011): “El terrorismo hace temblar Oslo”, Berlín, El País, 23/7/2011, p. 2. 
GÓMEZ, Juan (2011): "Este es vuestro último día, os voy a matar a todos hijos del diablo", Oslo, El País, 24/7/2011, pp. 1-7.

GÓMEZ, Juan (2012): "La fiscalía de Noruega acusa al ultra Breivik de terrorismo", Berlín, El País, 8/3/2012, p. 8.

GÓMEZ, Juan (2011):“Una granja idílica para hacer bombas”, Rena, El País, 25/7/2011, p. 3

GONZÁLEZ, Ricard (2011): "La conexión islamófoba estadounidense de Breivik", Washington, El Mundo, 20/7/2011, p. 20.

GABRIELSSON, Eva (2011): "La profecía de Stieg Larsson", en El Mundo, 26/7/2011, p.19.

GABRIELSSON, Eva (2011): Millenium, Stieg y yo. Barcelona, Destino.

GULSTAD, Ann-Louise (2012): “Carta a Anders B. Breivik”. El Mundo, 3/5/2012, pg. 21.

GULSTAD, Ann-Louise (2011): "Una bomba en la tierra de la paz" en El Mundo, 24/7/2011, p. 24.

HENLEY, Jon (2012): "El padre del monstruo. Es posible que la culpa sea mía", $E l$ Semanal, no $1282,20-26 / 5 / 2012$, pp. 38-42.

KOWALSKI, Piotr (2011): "Breivik compró en Polonia sustancias para las bombas", Varsovia, Público, 26/7/2011, pg. 9.

LAPUENTE GINÉ, Víctor (2011): "La clave es despertar igual que antes". El País, 24/7/2011, p. 7.

LARSSON, Stieg (2011): La Voz y la furia. Barcelona, Destino.

LARSSON, Stieg (2010): Millenium 1. Los hombres que no amaban a las mujeres. Barcelona, Destino.

LARSSON, Stieg (2010): Millenium 2. La chica que soñaba con una cerilla y un bidón de gasolin. Barcelona, Destino.

LARSSON, Stieg (2010): Millenium 3. La reina del palacio de las corrientes de aire. Barcelona, Destino.

LÓPEZ SANTOS, Miriam (2010): "La estetización de la violencia: génesis del cine negro nórdico (1990-2010)" en SÁNCHEZ ZAPATERO, Javier y MARTÍN ESCRIBÁ, Álex (eds.): El género negro: el fin de la frontera. Santiago, Andavira Editora, pp. 445-453.

LÓPEZ SANTOS, Miriam (2011): “Entre la novela negra y la estética gótica: La Generación Millenium". InterseXiones, vol. 2, pp. 181-198.

MAESTRO, Rosa y JIMÉNEZ, Yolanda (2012): “Ambiente de Suecia” en Iberia, Ronda Magazine. Madrid, 3/2012, pp. 76-86.

MAGNUS, Jon (2011): "Todo ardía en el infierno", -Relato en los segundos posteriores al ataque en la capital- Oslo, El Mundo, 23/7/2011, p. 22. 
MARTÍNEZ DE RITUERTO, Ricardo (2011): "Cuando Europa mira para otro lado", Bruselas, El País, 26/7/2011, p. 5.

MÜLLER, Enrique (2011): “Un hombre frío como el hielo”. Berlín, La Voz de Galicia, 24/7/2011, p. 3.

MURADO, Miguel Ángel (2011): “Crímenes sin un móvil claro”, A Coruña, La Voz de Galicia, 23/7/2011, p. 3.

MURADO, Miguel Ángel (2011): "Ideas demasiado familiares”, A Coruña, La Voz de Galicia, 26/7/2011, p. 17.

MURADO, Miguel Ángel (2011): "La nueva extrema derecha escandinava, el caldo de cultivo", A Coruña, La Voz de Galicia, 24/7/2011, p. 5.

NOME, Petter (2011): “A los que habéis alimentado al asesino", en El Mundo, 25/7/2011, p. 17.

PIERCE, William Luther (1978): The Turner Diaries. USA, NVB.

POOHL, Daniel (2011): "Una voz que echamos de menos", en La Voz y la furia. Barcelona, Destino, 2011, pp. 11-15.

POUSA, Luis (2011): "Stieg Larsson ya había alertado del auge de la ultraderecha nórdica", en La Voz de Galicia, 28/7/2011, p. 21.

POZA, Pedro (2011):“El fin de la inocencia”. Copenhague, El Mundo, 23/7/2011, p. 23.

POZA, Pedro (2011): “Una paz rota por la maldad latente". Copenhague, El Mundo, 25/7/2011, p. 24.

PRIETO, Joaquín (2011): "La herencia del asesino de Oklahoma”. El País, 25/7/2011, p. 5.

REINARES, Fernando (2011): “¿Para qué en Noruega?”. El País, 23/7/2011, p. 5.

ROJAS, Enrique (2011): "Psicópata y héroe a la inversa" en El Mundo, 25/7/2011, p. 17.

SIERRA, Javier (2011): "El falso templario". El Mundo, 2677/2011, p. 15.

TOHARÍA, José Juan (2011): "Palabras como puños, puños sin palabras". El País, 25/7/2011, p. 4.

VAQUER, Jordi (2011): "Democracia bajo ataque", El País, 26/7/2011, p. 6.

VÁZQUEZ SALLÉS, Daniel (2012): "Los santos de los últimos días". El Mundo, 24/7/2012, p. 25.

VIZCAÍNO, Javier (2011): “Un asesino como nosotros”. Público, 26/7/2011, p. 7.

ZSCHUNKE, Peter (2011): "Oslo aguanta la respiración" en La Voz de Galicia, Oslo/DPA, 24/7/2011, p. 4. 